accelerates, and then retards reaction, the final phase setting in the earlier the higher the nitrous acid concentration. For fixed concentrations of nitric acid, an increasing concentration of nitrous acid at first strongly accelerates, then retards, and then weakly accelerates nitration, the retardation setting in the earlier the higher the concentration of nitric acid. These statements apply to the general
conditions investigated, in which the concentration of nitrous acid was shown to remain constant during nitration.

The detailed presentation and analysis of these relations would be lengthy; but we may state our conclusions. They are, first, that nitric acid is doing three things : it is producing a strong nitrating. agent $\left(\mathrm{NO}_{2}^{+}\right) ;$it is converting the aromatic compound into a nitrationresisting oxonium ion; and it is helping nitrous acid to suppress $\mathrm{NO}_{2}+$ (by converting $\mathrm{N}_{2} \mathrm{O}_{4}$ into ions, in particular nitrate ion, as described in the first of these communications*). Secondly, nitrous acid is also doing three things : it is uniting with the phenol derisative to form a complex, which is highly reactive in nitration; it is, as already mentioned, co-operating with nitric acid to produce nitrate ion and thus to suppress $\mathrm{NO}_{2}+$; and, in the form $\mathrm{N}_{2} \mathrm{O}_{4}$ (or $2 \mathrm{NO}_{2}$ ), it is itself acting as a direct nitrating agent.

We think the complex may depend on univalent electron exchange ${ }^{1}$. Veibel $^{2}$ has already postulated an addition complex between phenol and nitrous acid. Arnall ${ }^{3}$ has previously assumed direct nitration by $\mathrm{N}_{2} \mathrm{O}_{4}$.

phenols, especially in aqueous solvents containing much before 2,4 , yet another mechanism enters, which has been considered evidence of this is that presence of as little nitrous acid as possible ( $\mathrm{PhOH}=1, \mathrm{HNO}_{3}=1$, $\mathrm{HNO}_{2}=0$ mol.) yields 0 - and $p$-nitrophenols in the approximate proportions $7: 3$, in the presence of a large amount of nitrons acid (for example, PhOH $=1, \mathrm{HNO}_{3}=1, \mathrm{HNO}_{2}=2$ mol.) the ratio becomes changed to $1: 9$, and this is the ratio in which $0-$ and $p$-nitrosophenols are formed if the nitric acid is omitted ${ }^{2}$ - $p$-Nitroso-
phenol has been isolated as a by-product from the latter nitrations.

A. BUNTON

E. D. HUGHES

R. I. REED

Sir William Ramsay and Ralph Forster Laboratories,

University College, London, Sept. 2

* Nature, 158, 448 (1946).

${ }^{1}$ Benford et al., Nature, 156, 683 (1945). Kenner, Nature, 156, 369 (1945) ; 15\%, 340 (1946)

'Ber., 63, 1577 (1930). Z. phys. Chem., B, 10, 22 (1930).

${ }^{3} J$. Chem. Soc., 123, 3111 (1923).

'Kartaschev, J. Russ. Phys.-Chem. Soc., 59, 819, 833 (1927); 62, 385,2129 (1930).

\section{Organic Nitrogen Compounds as Nitrogen Nutrition for Higher Plants}

IN sterile cultures pea and clover use especially well aspartic and glutamic acids for their nitrogen nutrition, as demonstrated by previous experiments in this laboratory ${ }^{1}$. Both the optical forms are utilized ${ }^{2}$. If the nutrient solution contains aspartic acid as well as nitrate and ammonium sulphate, all these nitrogen sources are utilized simultaneously (see accompanying table). Aspartic acid thus competes with nitrate and ammonium nitrogens as a nitrogen source for peas, an important fact to be borne in mind when discussing the ability of plants to utilize organic nitrogen in natural conditions. Nitrogen nutrition has a marked effect on the structure of pea roots. Peas grown on nitrate nitrogen and without nitrogen form in this respect a special group; peas grown on aspartic acid nitrogen, on ammonium nitrogen and on nitrogen supplied by root nodules another.

Furthermore, we have confirmed the earlier observations that when the pea uses aspartic acid for its nitrogen nutrition, nitrogen and carbon disappear from the solution in the same proportion ${ }^{3}$ and that no essential change occurs in the $p \mathrm{H}$ of the solution and no ammonia can be detected in the nutrient solution. In aspartic acid the ratio of earbon to nitrogen is $3 \cdot 43$; in the nutrient solution which originally contained $50 \mathrm{mgm}$. aspartic acid nitrogen and at the end of the experiment $16.6 \mathrm{mgm}$, nitrogen (all the remaining nitrogen being amino nitrogen) the amount of or (anic the ratio $\mathrm{C} / \mathrm{N}=3 \cdot 48$. The position was the same, when the nutrient solution contained besides aspartic acid also nitrate. The ratio of $\mathrm{C}$ to $\mathrm{NH}_{2}-\mathrm{N}$ in the nutrient solution was thereby likewise 3.48 . The to $\mathrm{NH}_{2}-\mathrm{N}$ in the nutrient solution was thereby likewise $3 \cdot 48$. The results confirm the previous investigations of this laboratory which is being utilized. Not until it reaches the root cells does the trans- formation of aspartic acid take place (through deamination ansamination, etc.).

With plants of the family Gramineæ (wheat and barley as test plants) aspartic and glutamic acids do not tunction as $\mathrm{N}$-source according to the previous findings of this laboratory ${ }^{1}$. The entirely different behaviour of legumes and non-legumes towards amino dicarbonic
acids is especially noteworthy since certain other amino-acids, for acids is especially noteworthy since certain other amino-acids, for example, $\alpha$-alanine and glycocol, are utilizable also by wheat and barley. In our new experiments, very similar results have been obtained as in the previous ones. In one experiment the wheat grown in different nitrogen nutrition media contained the following amounts of nitrogen : without nitrogen nutrition $3.2 \mathrm{mgm}$., on aspartic acid $2.9 \mathrm{mgm}$., on glutamic acid $3.3 \mathrm{mgm}$., on nitrate $22.2 \mathrm{mgm}$., on glycocol $10.5 \mathrm{mgm}$., on $\alpha$-alanine $6.8 \mathrm{mgm}$., on cystine $7.6 \mathrm{mgm}$. The a mount of nutrient solution was in all experiments $20 \mathrm{mgm}$. per plant. Some other amino-acids were taken up in certain degree, but in spite of that no growth occurred which would have resulted in the rise of dry matter yield. Aspartic and glutamic acids which in some experiments were taken up in very small amounts, 1-2 mgm. nitrogen per plant, lower appreciably the dry weight of plants. Evidently thev acrelerate respiration. Since the transamination takes place in Graminex as easily as in leguminous plants (our results in this respect are in good agreement with those of (edrangolo and (Uarandante ${ }^{4}$ ), the ineffectiveness of aspartic and glutamic acids is difficult to explain.

Moreover, it has been noted that if the wheat is given in sterile nutrient solution besides aspartic acid also nitrate and ammonium sulphate (each providing $22 \mathrm{mgm}$. nitrogen, total nitrogen supply per plant $66 \mathrm{mgm}$.) the wheat does not grow. The cause for this is being investigated.

Regarding the utilization of amino-acids other than aminodicarbonic acids by leguminous plants it may be mentioned that the utilization of glycocol by pea is noticeably good. $\alpha$-Alanine is utilized to a certain extent, but it often causes a curious branching and shortening of internodes. The growth of pea is compara

$\mathrm{HN}_{3}$ removed) and Witte pepton. In the light of our laboratory experiments, especially the new nitrate and ammonia nitrogen, it seems probable to us that in natura conditions plants use also , in natural nitrogen nutrition, at least in certain soils. As a rule, however, the uptake of organic nitrogen by cultivated plants is not great, since ammonium salts and nitrates are rapidly formed from organic nitrogen compounds in soil. Since, however, the uptake of organic nitrogen compounds even in small amounts may affect the plants markedly, the significance of these nitrogen compounds can be great. In the foregoing, alanine has been noted to cause pronounced changes in the shape of pea, and phenyl ethylamine, the decarboxylation product of phenylalanine, which has been added to nitrate-containing nutrient solution, has produced a branching of different type in pea. Effects of this kind can be expected to occur under certain conditions also in Nature. ARTTURL I. VIRTANEN

Biochemical Institute,

Helsinki. July 5 .

1 Virtanen, A. I., Report 18th Scand. Naturalist Congr. Copenhagen 540 (1929). Förhandl. 4 Nord. Kem. Kongr. Oslo, 137 (1932). Virtanen, A. I., v. Hausen, S., and Karström, H., Biochem. ZZ., 258, 106 '(1933).

2 Virtanen, A. I., and Arhimo, A. A., unpublished data (1939).

3 Virtanen, A. I., Ber. N.J.F. Kongres Kobenhavn, 203 (1935).

Cedrangolo, F., and Carandante, G., Boll. soc. ital. biol. sper., 15 $482(1940)$

\section{Botanical Origin of Tube-Curare}

dextro-Tubocurarine chloride was flrst isolated in crystalline form from native tube-curare ${ }^{1}$. It has since become a valuable adjunct in anæsthesia ${ }^{2}$. The chemical constitution of dextro-tubocurarine chloride and its relation to bebeerine ${ }^{3}$ suggests that its botanical origin lies in some species of Chondrodendron. Through the kindness of $\mathrm{Mr}$. J. W. Massey, British consul in Iquitos, the stem and leaves of Chondrodendron tomentosum Ruiz and Pavon, collected by the late Guillermo Klug at Tarapoto in Peru, have been made available. The leaves were identified by Mr. N. Y. Sandwith of the Herbarium, Kew, as belonging to this species, and on chemical examination the stems yielded lovo-curine ( $l$-bebeerine) and lovo-tubocurarine chloride. The latter was fourd by Dr. B. D. Burns to have a curare action on the rat's diaphragm, which was very weak when compared with that of dextro-tubocurarine chloride.

On the other hand, Dutcher ${ }^{4}$ has examined a native Upper Amazonian curare prepared from $\mathrm{Ch}$. tomentosum and has isolated dextro-tubo-

TORSDAG-PEA GROWN ON DIFFERENT N-NUTRITION IN STERILE WATER OULTURES. ONE PLANT IN EACH FLASK CONTAINING 1 I. NUTRIENT SOLUTION, Sterile PLANTS Werf transferRed to CULTURE FI,ASKS JANTARY 19-21, 1946.

\begin{tabular}{|c|c|c|c|c|c|c|c|c|c|c|}
\hline \multirow{12}{*}{$\begin{array}{l}\quad \text { Quality of } \mathrm{N} \text {-nutrition } \\
\text { Amount of } \mathrm{N} \text {-nutrition, } \mathrm{N} \text { (mgm.) } \\
\text { Number of days } \mathrm{N} \text {-nutritiongiven } \\
\text { Dry weight of plant (mgm.) } \\
\mathrm{N} \text { in plant (mgm.) } \\
\mathrm{N} \text { in \% of dry matter } \\
\mathrm{Final} \mathrm{pH} \text { of the nutrient soln. } \\
\mathrm{NO}_{3}-\mathrm{N} \text { used (mgm.) } \\
\mathrm{NO}_{3} \mathrm{~N} \text { in \% of total } \mathrm{N} \text { used } \\
\mathrm{NH}_{4}-\mathrm{N} \text { used (mgm.) } \\
\mathrm{NH}_{4}-\mathrm{N} \text { in \% of total } \mathrm{N} \text { used } \\
\mathrm{NH}_{2}-\mathrm{N} \text { used (mgm.) } \\
\mathrm{NH}_{2}-\mathrm{N} \text { in \% of total } \mathrm{N} \text { used }\end{array}$} & \multicolumn{4}{|c|}{$\begin{array}{c}\left(\mathrm{NH}_{4}\right)_{2} \mathrm{SO}_{4}+\mathrm{Ca}\left(\mathrm{NO}_{3}\right)_{2}+\text { Aspartic acid } \\
50+50+50\end{array}$} & \multicolumn{4}{|c|}{ 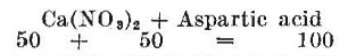 } & \multicolumn{2}{|c|}{$\begin{array}{c}\left(\mathrm{NH}_{4}\right)_{2} \mathrm{SO}_{4}+\text { Aspartic acid } \\
50+50=100\end{array}$} \\
\hline & 14 & 22 & 28 & 35 & 14 & 22 & 28 & 35 & 22 & 38 \\
\hline & 919 & 1789 & 2589 & 2987 & 857 & 1989 & 1823 & 2792 & 487 & 688 \\
\hline & $48 \cdot 3$ & $86 \cdot 6$ & $108 \cdot 7$ & $118 \cdot 9$ & $38 \cdot 9$ & $61 \cdot 2$ & $49 \cdot 8$ & $64 \cdot 3$ & $27 \cdot \mathrm{s}$ & $42 \cdot 4$ \\
\hline & $5 \cdot 2$ & $4 \cdot 9$ & $4 \cdot 0$ & $4 \cdot 0$ & $4 \cdot 5$ & $3 \cdot 1$ & $2 \cdot 7$ & $2 \cdot 3$ & $5 \cdot$ & $6 \cdot 2$ \\
\hline & $6 \cdot 1$ & $6 \cdot 1$ & $6 \cdot 5$ & $6 \cdot 8$ & $6 \cdot 9$ & $6 \cdot 9$ & $7 \cdot 5$ & $\overline{7} \cdot 4$ & $6 \cdot 3$ & 6.0 \\
\hline & $10 \cdot 8$ & $23 \cdot 1$ & $25 \cdot 8$ & $26 \cdot 0$ & $19 \cdot 6$ & $33 \cdot 1$ & $26 \cdot 2$ & $37 \cdot 4$ & & \\
\hline & $22 \cdot 8$ & $28 \cdot 6$ & $24 \cdot 2$ & $22 \cdot 4$ & $55 \cdot 7$ & $61 \cdot 1$ & $54 \cdot \overline{8}$ & $63 \cdot \overline{7}$ & & \\
\hline & $16 \cdot 5$ & $31 \cdot 5$ & $40 \cdot 8$ & $49 \cdot 0$ & & & & & $13 \cdot 6$ & $21 \cdot 2$ \\
\hline & $34 \cdot 9$ & $39 \cdot 1$ & $38 \cdot 2$ & $42 \cdot 1$ & & & & & 69. & $53 \cdot 1$ \\
\hline & $20 \cdot 0$ & $26 \cdot 0$ & $40 \cdot 0$ & $41 \cdot 3$ & $15 \cdot 6$ & $21 \cdot 1$ & $21 \cdot 5$ & $21 \cdot 3$ & $6 \cdot 0$ & $18 \cdot 7$ \\
\hline & $42 \cdot 3$ & $32 \cdot 3$ & $37 \cdot 6$ & $35 \cdot 5$ & $44 \cdot 3$ & 38.9 & $45 \cdot 2$ & $36 \cdot 3$ & $30 \cdot$ & $46 \cdot 9$ \\
\hline Total used $\mathrm{N}$ (mgm.) & $47 \cdot 3$ & $80 \cdot 6$ & $106 \cdot 6$ & $116 \cdot 3$ & $35 \cdot 2$ & $54 \cdot 2$ & $47 \cdot 7$ & $58 \cdot 7$ & $19 \cdot$ & $39 \cdot 9$ \\
\hline
\end{tabular}

